\title{
What is the environment in environmental health research? Perspectives from the ethics of science
}

\author{
David M. Frank \\ Department of Philosophy, Cogut Institute for the Humanities, Brown University, Providence, RI 02902, USA
}

\section{A R T I C L E I N F O}

\section{Keywords:}

Environmental health

Environmental justice

Science and values

Research ethics

\begin{abstract}
A B S T R A C T
Environmental health research produces scientific knowledge about environmental hazards crucial for public health and environmental justice movements that seek to prevent or reduce exposure to these hazards. The environment in environmental health research is conceptualized as the range of possible social, biological, chemical, and/or physical hazards or risks to human health, some of which merit study due to factors such as their probability and severity, the feasibility of their remediation, and injustice in their distribution. This paper explores the ethics of identifying the relevant environment for environmental health research, as judgments involved in defining an environmental hazard or risk, judgments of that hazard or risk's probability, severity, and/ or injustice, as well as the feasibility of its remediation, all ought to appeal to non-epistemic as well as epistemic values. I illustrate by discussing the case of environmental lead, a housing-related hazard that remains unjustly distributed by race and class and is particularly dangerous to children. Examining a controversy in environmental health research ethics where researchers tested multiple levels of lead abatement in lead-contaminated households, I argue that the broader perspective on the ethics of environmental health research provided in the first part of this paper may have helped prevent this controversy.
\end{abstract}

\section{Introduction}

Environmental health research produces scientific knowledge about environmental hazards and risks crucial for public health and environmental justice movements that seek to prevent or reduce exposure to these risks. The environment in environmental health research is conceptualized broadly as the range of possible social, biological, chemical, and/or physical hazards or risks to human health, some of which merit study due to factors such as their probability and severity, the feasibility of their remediation, and injustice in their distribution (Bullard, 1999; Resnik \& Roman, 2007; Resnik, 2012; Shrader-Frechette, 2002). This paper will discuss the ethics of identifying the relevant environment in environmental health research, as judgments involved in defining an environmental hazard or risk, judgments of that hazard or risk's probability, severity, and/or injustice, as well as the feasibility of its remediation, are all value-laden. Here by 'value-laden' I mean these judgments ought to be justified by appealing to non-epistemic values as well as epistemic values, especially because these judgments can lead to the promotion of some non-epistemic values at the expense of others (Douglas, 2016; Ward, 2020). In Section 2 I draw on the literature on values in science and research ethics to establish that science is thoroughly, normatively value-laden. Environmental health researchers ought to make multiple non-epistemic value judgments when they identify the relevant environment by choosing some hazards or risks as important to study, locating them within a causal model, operationalizing risk concepts, and analyzing their data (Douglas, 2000; Resnik \& Roman, 2007; Korthals, 2011; Elliott 2009, 2011, 2017; Shamoo \& Resnik, 2015). I argue that identifying the relevant environment for environmental health research involves complex tradeoffs between epistemic and non-epistemic values and requires coupling ethical and epistemic analysis (Tuana, 2013; Katikireddi \& Valles, 2015; Valles, 2018). In Sections 2 and 3 I illustrate by analyzing environmental lead research and a controversy in environmental health research ethics, the Kennedy Krieger Institute (KKI) lead abatement study. In the 1990s, KKI researchers tested multiple levels of lead abatement in lead-contaminated households in Baltimore, Maryland, USA (Murphy, 2004; Markowitz \& Rosner, 2013). The study was controversial because the researchers tested cheaper and possibly less-effective methods of lead abatement when known-effective but more expensive lead abatement methods were available. Specific controversies included the definition of 'minimal risk' in environmental health research ethics (Wendler, 2004) and the extent to which the researchers were complicit in environmental

E-mail address: david_frank@brown.edu. 
racism/injustice or working to improve the lives of those facing environmental injustice (Buchanan \& Miller, 2006). I argue that the broader perspective on the ethics of environmental health research provided in the first part of this paper may have helped prevent this research ethics controversy, by encouraging researchers to collaborate with community members to fully contextualize the environmental lead hazard.

The explicit coupling of ethics and epistemology throughout research suggests broader roles for relevant participant communities in formulating research goals and methods, a position articulated by scientists reflecting on ethical issues of housing-related research involving children, especially those raised by the KKI study (Lo and O'Connell, 2005), and standard in community-based participatory research (CBPR) frameworks (Israel et al., 2005). While community-based participatory environmental health research raises further ethical and logistical challenges for researchers, it also encourages approaches to research ethics that center ongoing relationships between scientists and participants, a perspective Cordner et al. (2012) call "reflexive research ethics." Section 4 concludes by discussing how such a relational approach to research ethics for environmental health might approach identifying the relevant environment for environmental health research while avoiding or mitigating possible further harms of stigmatization involved in what Tuck (2009) and Murphy (2017) critique as "damage-centered research."

\section{Identifying the relevant environment in environmental health research: roles for non-epistemic values}

\subsection{Science is thoroughly value-laden: non-epistemic values throughout science}

It is a truism that scientists are social actors with ethical obligations to research participants and the broader society whose resources make their research activities possible (Shamoo \& Resnik, 2015). Furthermore, as social actors scientists are implicated in relations of social, political, economic, and technological power, raising more complicated ethical-epistemic issues related to science's "dual nature" as a socially situated and thus partial producer of knowledge (Levins, 1996). Both realist and anti-realist philosophers of science agree that science aims at some distinctly cognitive, epistemic, or knowledge-related goals or values, for example true or approximately true theories and explanations (realism) or empirically adequate/predictive theories (anti-realism/instrumentalism). Indeed, Kuhn (1977) characterized scientific theory choice in physics as an epistemic value judgment appealing to some complex combination of "accuracy, consistency, scope, simplicity, and fruitfulness," (322) where reasonable scientists might disagree about the weight of these considerations in difficult cases. However, because scientists are social actors, non-epistemic or "contextual" values, for example human and non-human health and well-being, social justice, and sustainability, are relevant throughout scientific practice (Elliott and McKaughan, 2014). Insofar as all scientists face resource constraints, they are forced to consider trade-offs between epistemic and non-epistemic values. It is also uncontroversial that non-epistemic values are ethically relevant to choosing a research topic and methodology, as such values motivate and/or justify studying particular "problems" and restrict methodological choices. The choice to study childhood lead poisoning is clearly justified by non-epistemic concerns about children's health and well-being as well as environmental racism and injustice (Bullard, 1999; Markowitz \& Rosner, 2013; Whitehead \& Buchanan, 2019), and research ethics restricts permissible methods of data collection and experimentation, especially those involving children and other vulnerable populations (Lo and O'Connell 2005, Shamoo and Resnik, 2015).

Philosophical views on the normatively appropriate roles of nonepistemic values "within" scientific practice-in operationalizing concepts, characterizing and analyzing data, statistical inference, etc.-are more controversial (Douglas, 2016). The "value-free ideal" attempts to avoid epistemic pathologies related to motivated reasoning, "wishful thinking," manufactured doubt, cultural prejudice, etc. that can result in some cases when non-epistemic values affect epistemic practices supposedly "internal" to science (Douglas 2009, 2016; Elliott, 2017). Being an ideal, even its proponents might agree that the value-free ideal is rarely, if ever, achievable. Sociologists and historians of science, as well as feminist epistemologists and philosophers of science, have long argued that the influence of non-epistemic social and cultural values is pervasive and unavoidable in areas deeply "internal" to scientific practice (Haraway, 1989; Longino, 1990; Anderson, 2020). While these could be seen as "descriptive" challenges to the value-free ideal, or the claim that non-epistemic values often serve as explicit or implicit "motivating reasons" for epistemic choices (Ward, 2020), many of these same scholars have also challenged the value-free ideal at a normative level (Douglas, 2016). That is, non-epistemic values ought to serve as "justifying reasons" for such choices, especially since such choices have downstream consequences on important values (Ward, 2020). For example, feminist philosophers of science have discussed legitimate roles for non-epistemic values in choice and weight of epistemic values (Longino, 1995), choice of background assumptions and conceptual frameworks (Longino, 1990), and the development and deployment of concepts and categories (Anderson, 2020). Notably, Heather Douglas (2000, 2009) revived Rudner's (1953) argument that "the scientist qua scientist makes value judgments," since they must manage and trade off "inductive risks" associated with different kinds of error, i.e. Type-I vs. Type-II error or William James's) failing to believe the truth vs. believing something false (James, 1979). To illustrate, consider Rudner's comparison between testing a hypothesis about the integrity of belt buckles with testing a hypothesis about the safety of a drug. The "burden of proof' for accepting a scientific hypothesis ("these belt buckles are not faulty" vs. "this drug is safe"), or the alpha-level in classical statistical hypothesis testing, clearly ought to be influenced by the practical stakes, or the risks of being wrong in different ways, and often is encoded within disciplinary conventions of statistical inference. ${ }^{1}$ Drawing on Douglas's and others' work, a more general version of this inductive risk argument against the value-free ideal is roughly that (1) epistemic/methodological decisions often raise non-epistemic risks; (2) scientists, as moral agents, have an obligation to consider the likely consequences of their actions, including risks; (3) therefore scientists have an obligation to consider non-epistemic values in their epistemic/methodological decisions, a conclusion that is incompatible with the value-free ideal qua normative ideal. In other words, if epistemic choices have important non-epistemic consequences, these consequences ought to be taken into account in the justification of those choices. $^{2}$ These methodological decisions go beyond choice of research topic and protection of human and non-human participants and may include operationalization of concepts, characterization of data, statistical analysis, and interpreting results. Thus science is thoroughly value-laden, not just because scientists cannot insulate epistemic from non-epistemic considerations in their work, but because they ought not.

To illustrate Rudner-Douglas-style inductive risk, consider a practical context of environmental health research on the efficacy of lead abatement techniques without human participants that assessed whether a technique effectively decreases lead dust in a home (e.g. the first part of Farfel \& Chisolm, 1990, analyzed below). Researchers' epistemic choices may be intended to minimize false positives, i.e. minimize the chance of

\footnotetext{
${ }^{1}$ While some philosophers of science like Jeffrey (1956) and Betz (2013) respond by claiming that scientists ought to simply make uncertainties explicit to allow decision-makers to manage inductive risks themselves, this same inductive risk argument can be extended to methodological decisions within Bayesian statistics and "higher order" uncertainty about explicit estimates of scientific uncertainty, especially in real-world contexts where scientists act as policy advisors in non-ideal informational settings (Steele, 2012; Frank, 2017, 2019).

${ }^{2}$ Using Ward's (2020) helpful taxonomy of values in science, this argument includes both the claim that epistemic choices causally affect non-epistemic values and the claim that such choices ought to be justified partly by appeal to the latter.
} 
concluding falsely that an abatement technique effectively reduces lead-contaminated dust. However decided by some combination of disciplinary convention and conscious choice (i.e., whatever the scientists' motivating reasons or the psychological and sociological causes of these choices), this may have non-epistemic risks, for example in reducing the likelihood of abatement, insofar as such research might be used to propose or guide policy and epistemic conservatism might justify delay. Similarly, consider an "epistemically conservative" interpretation of results that show efficacy of some method in reducing lead dust that would question whether we could infer that this method would reduce blood lead levels in children living in households abated by those methods. This epistemic attitude also implies a particular balance of non-epistemic inductive risks. Conversely, pursuit of non-epistemic values like ethical restrictions on permissible methodologies will have epistemic consequences, for example making it easier or more difficult to test efficacy of abatement techniques. Given the values at stake in environmental health research, it is not surprising that environmental justice movements emphasize that the "burden of proof" should be placed on polluters to establish that their practices are safe for affected communities, not on those communities to establish that those practices are dangerous (Bullard, 1999; Shrader-Frechette, 2002).

Since epistemic and non-epistemic values are so entangled in practice-indeed, some philosophers go so far as to deny a meaningful distinction between these (e.g. Longino, 1996) - the relevant normative questions then become which non-epistemic values should be considered, and how these should or should not be balanced against epistemic values in various contexts. As discussed by Katikireddi and Valles (2015), categorizing variables in public health research often raises complex ethical and epistemic issues that interrelate, requiring "coupled" ethical-epistemic analysis (Tuana, 2013). In particular, they discuss non-epistemic risk of promoting stigma in public health research, for example in categorizing certain neighborhoods as "deprived," an issue clearly relevant to environmental public health research and one which I return to in the concluding discussion. I now turn to the value judgments inherent in identifying the relevant environment for environmental health research, focusing on roles for non-epistemic values.

\subsection{Non-epistemic values in identifying the relevant environment: the case of environmental lead}

As mentioned in the introduction, environmental health researchers define 'the environment' broadly to include the range of possible social, biological, chemical, and/or physical hazards or risks to human health. Non-epistemic values are relevant to which hazards are identified, how their causes are understood, and how they are quantitatively modeled by scientific researchers. Resnik and Roman (2007, Table 1) distinguish various categories of causes of environmental health inequalities, or descriptive differences in health outcomes between people or groups, that may constitute normatively unjust inequities depending on their causes and a particular conception of justice. These categories, not meant to be mutually exclusive, include physical causes ("sanitation, pollution, geography, natural disasters, pests, physical infrastructure, housing, workplace hazards, pesticides, diet"), social causes ("race, ethnicity, gender ... war, education, literacy, institutions ..."), cultural causes ("religion, morality ..."), economic causes ("income, wealth, markets, taxation ... employment conditions"), and legal causes ("environmental regulations, anti-discrimination laws ... public health laws ..."). The sheer quantity and variety of environmental factors and their interactive complexity in causally contributing to health outcomes and inequalities makes environmental public health research and epidemiological research particularly epistemically difficult, but also raises non-epistemic issues in identifying environmental hazards in the first place, especially when researchers' choices prioritize particular causes of health (Valles, 2018, ch. 5). It is worth noting at the outset that 'environmental hazard' is a concept that includes both descriptive and evaluative content, not unlike so-called "thick concepts" (Väyrynen, 2019). However, I argue further that identification of an environmental hazard and its location within researchers' implicit causal model, as well as subsequent quantitative measures of that hazard's risk, also ought to include non-epistemic ethical judgments about justice and the political and economic feasibility of interventions. As environmental health research is intended to be useful for policy and decision-making, the inductive risk argument outlined above further complicates any attempt to insulate the inner workings of such research from non-epistemic values. The example of research on the environmental health hazards associated with lead paint is an instructive example that helps set up the context for the discussion of the controversial KKI lead abatement study in the next section. I thus first turn to a brief history of the public health disaster of environmental lead.

Despite its known toxicity, in the early 20th century lead was added to gasoline, paint, and other products, leading to a public health disaster in the United States and elsewhere in which millions of children suffered acute lead poisoning or the various neurobehavioral problems associated with lower-level chronic exposure (Markowitz \& Rosner, 2013; Rosner \& Markowitz, 2016; Benfer, 2017). As medical research built up support for the claim that even small amounts of environmental lead were toxic to the developing brain, the lead industry engaged in a public-relations campaign to divert attention and prevent effective lead regulation for decades. By the 1960s, grassroots community and civil rights movement organizations called attention to lead poisoning as an example of what would eventually be termed environmental racism (Rosner \& Markowitz, 2016). After the 1970s, regulations removing lead from gasoline and banning lead-based paint in the US, along with some successful state and municipal abatement programs, dramatically reduced the overall burden of lead: in a nationally representative survey of the US in the late 1970 s, $78 \%$ of people ages 1-74 and $88 \%$ of children ages 1-5 had blood lead levels of $10 \mu \mathrm{g}$ per deciliter $(\mu \mathrm{g} / \mathrm{dL})$ or higher, but the geometric mean blood lead level decreased from $12.8 \mu \mathrm{g} / \mathrm{dL}$ in the late $1970 \mathrm{~s}$ to $0.82 \mu \mathrm{g} / \mathrm{dL}$ by 2015-2016 (Dignam et al., 2019, S13-S14). Globally, much of the current health burden of lead poisoning now exists in the Global South (Flora et al., 2012). However, even in the US, hundreds of thousands of housing units built before 1978 still contain lead-based paint and present a hazard to children, especially in the form of deteriorating paint and lead-contaminated dust that might be inhaled or ingested due to children's normal exploratory and play behaviors, especially hand-to-mouth activity (Benfer, 2017). Recent surveys reveal that at least 500,000 children ages $1-5$ in the US have blood lead levels at or above $5 \mu \mathrm{g} / \mathrm{dL}$, the CDC's current "reference value" that triggers public health response, although the current medical consensus is that there is no safe level of lead in a child's blood (Dignam et al., 2019). Children with low levels of lead in their blood, even below $5 \mu \mathrm{g} / \mathrm{dL}$, are more likely than their peers to suffer behavioral and learning problems, although lead's toxic effects are not limited to the nervous system (Markowitz \& Rosner, 2013). The recent case of lead poisoning in Flint, Michigan demonstrates that lead hazards in drinking water also persist due to lead in plumbing infrastructure, particularly if water is corrosive or untreated. The egregiously slow and inadequate response of governmental authorities to the lead-contaminated drinking water in majority-African American Flint-including outright denial of the problem early on-was also widely interpreted as an instance of environmental racism (Benz, 2017). The broader society's refusal to comprehensively deal with the legacy of lead hazards in old housing stock, plumbing, and soil by actions that would prevent exposure before poisoning occurs (Markowitz and Rosner [2013,1] call this "a legacy of neglect"), and the resulting inequalities in chronic, low-level exposure to this neurotoxin by race and class, raise similar charges of environmental injustice and environmental racism (Benfer, 2017; Bullard, 1999; Markowitz \& Rosner, 2013; Rosner \& Markowitz, 2016; Shrader-Frechette, 2002). Furthermore, the controversies around the lead abatement research discussed below can only be understood within the broader context of the history of racism in American medicine and biomedical research (Roberts, 2012; Washington, 2006), 
particularly the infamous Tuskegee research scandal in which African American men with syphilis were deceived into participation in a purely observational study and prevented from receiving effective treatment (Brandt, 1978).

Indeed, the health hazard of deteriorating lead paint in older housing stock is not merely "physical," but is also a manifestation of broader, interacting social forces of racism, housing segregation (e.g. redlining in the US), and poverty, with poor children and children of color suffering disproportionate risk (Benfer, 2017; Bullard, 1999; Whitehead \& Buchanan, 2019). Non-epistemic and ethical judgments about the value and importance of children's health and the injustice of poor children and children of color continuing to disproportionately suffer from this entirely preventable hazard clearly justifies resources for research. However, the identification of lead paint dust or deteriorating lead paint itself as the relevant environmental health hazard, as opposed to broader sociopolitical or economic contexts implicated in the persistence and distribution of this preventable housing hazard, characterizes the relevant environment narrowly in terms of the hazard's most proximate cause. Epistemically, this reductionist strategy of identifying a hazard's most proximate cause makes tractable a wide variety of research questions, some aimed primarily at harm reduction or "secondary prevention, " i.e. detecting hazard exposure as early as possible and reducing its harms, whereas the main goal of public health research has historically been primary prevention, i.e. preventing hazard exposure in the first place (Markowitz \& Rosner, 2013). Alternatively, more holistic characterizations of the relevant environment that include in researchers' causal model of the lead hazard sociopolitical or economic factors implicated in the continued presence and distribution of the hazard are more naturally associated with primary prevention through political strategies of collective action to influence housing policy or to prompt society to subsidize full lead abatement. On the other hand, researchers' (justified or unjustified) pessimism about society's willingness to pay upfront costs for primary prevention of low-level chronic exposure when existing economic incentives are such that landlords for low-income housing would be more likely to abandon a home than pay to perform lead abatement, may motivate narrower characterizations that lend themselves to research on secondary prevention or even "cost-effectiveness" of secondary prevention, discussed in the next section (Lo and O'Connell 2005). Relatedly, in his recent work on prioritizing causes in population health science, Valles (2018, ch. 5) discusses Rose's (1985) distinction between the proximate causes of cases of disease and the more holistic or structural causes of incidence, or differences in health between populations. Valles argues that population health researchers should prioritize the latter, both because of strong scientific evidence for the robust causal significance of social and environmental determinants of health-these are "fundamental causes" in the sense of Link and Phelan (1995)_but also because of population health researchers' non-epistemic commitment to promoting health equity between populations.

This all suggests that in addition to ethical judgments about the severity of a hazard and its injustice that justify research, locating the cause of a hazard in environmental health research implies a variety of non-epistemic political and ethical judgments about the feasibility of interventions and possibilities for social change (Anderson, 2020). These feasibility judgments tied to the researchers' causal model of the study system are not merely narrow, technical judgments-e.g. about physical, chemical, or biological possibility-but are partly constitutive of ethical and political worldviews, including judgments of ethical responsibility within relationships of power. Marxist biologists Richard Levins and Richard Lewontin pointed this out in their (1985) defense of a "dialectical" approach to evolutionary biology and ecology:

[T] o do science is to be a social actor engaged, whether one likes it or not, in political activity. ... whether the cause of tuberculosis is said to be a bacillus or the capitalist exploitation of workers ... can be decided objectively only within the framework of certain sociopolitical assumptions
... Scientists, whether they realize it or not, always choose sides. (Levins \& Lewontin, 1985, 4-5, emphasis added)

Their provocative example of the cause of tuberculosis (TB) is not meant to question the germ theory-the proximate cause of TB is indeed Mycobacterium tuberculosis infection-but rather to point to the causal roles of the broader social and environmental determinants of health in which such infectious diseases are able to spread and cause illness, particularly living and working conditions (Lönnroth et al., 2009; Valles, 2018, p. 114). According to this argument, researchers' causal model of social systems implicitly encode characteristically ethical judgments of political and ethical responsibility, both because they have downstream effects on attributions of responsibility and arguably ought to be justified by such judgments. Indeed, one of the lead industry's main rhetorical strategies in arguing against regulation was to blame the parents, especially mothers, of lead-poisoned children (Rosner \& Markowitz, 2016, p. 324). If environmental health researchers are indeed "choosing sides" when they identify a hazard worth studying and delimit its cause-lead paint dust, racism, capitalism, poverty, housing policy, etc.-their identification of the relevant environment cannot be insulated from non-epistemic values.

Once an environmental hazard and relevant causal factors are identified in environmental health research, the development of quantitative measures of environmental risk - usually understood as a function of the probability and severity of an environmental hazard-raise further ethical issues related to both the inductive risk argument as well as broader concerns about justice. To start with justice, while quantitative measures of risk do not logically presuppose that there is a threshold level of "acceptable" or "tolerable" risk, whether because the probability is small enough, the costs of reducing the risk exceed the benefits, people tolerate similar levels of risk voluntarily, etc. (Hunter \& Fewtrell, 2001), they can suggest as much because risk quantification allows risks to be made commensurable and compared across contexts, and quantification of risk is epistemically unnecessary when known hazards are seen as categorically unacceptable. An alternative environmental justice approach would suppose that certain risks, for example risks to children posed by environmental lead, are unjustifiable and unacceptable at any level, a characteristically deontological ethical judgment which may ethically rule out certain kinds of risk modeling, risk assessment, and cost-benefit analysis in environmental health research. Similarly, defining a threshold for 'lead poisoning' itself in biomedical research involves ethical judgments. Consider that the US Center for Disease Control's threshold "reference value" for lead poisoning that should trigger public health action has changed several times: initially defined at a blood lead level of $60 \mu \mathrm{g} / \mathrm{dL}$, a level sufficient to cause death or severe disability, it was lowered to $40 \mu \mathrm{g} / \mathrm{dL}$ in 1971, but by 1991 had been lowered to $10 \mu \mathrm{g} / \mathrm{dL}$, and now stands at $5 \mu \mathrm{g} / \mathrm{dL}$, despite the fact that no level of lead is safe for children and many researchers believe it should be set at the lowest reliably detectable level of around $2 \mu \mathrm{g} / \mathrm{dL}$ (Gilbert \& Weiss, 2006). While this trend is in part due to advances in biomedical knowledge about the effects of lead at low doses, it also clearly reflects ethical "threshold" judgments. Coupled ethical-epistemic analysis is thus necessary to define environmental risk thresholds and possibly limit their use in environmental health research.

Furthermore, insofar as methodological/epistemic research decisions in environmental hazard risk analysis err on the side of over- or underestimating the severity or probability of a particular hazard, and such research might be used in policy or decision-making, the inductive risk argument shows there ought to be a role for non-epistemic values in justifying these decisions. Johns Hopkins and KKI lead researchers Mark Farfel and Julian Chisolm, investigators on the controversial abatement study discussed in the next section, showed in some of their earlier work that then-commonly-used methods of abatement were largely ineffective and sometimes counterproductive at reducing blood lead levels in children (Farfel \& Chisolm, 1990). This particular study was an observational prospective study or "natural experiment" that compared "traditional" 
with "modified" lead abatement practices in homes with children affected by environmental lead from paint. Modified practices included "more than minimal efforts to clean the dwelling following abatement, dispose of debris off-site, and to protect workers, occupants, and their belongings" (1240) and the use of a heat gun instead of torch and/or sander on deteriorated paint. They found that traditional abatement methods often caused greater exposure due to the generation of further dust by abatement which was often not adequately cleaned up, while modified methods reduced lead dust and blood lead in children temporarily but not after six months (Farfel and Chisolm, 1990). These results should not have been surprising to these researchers since Farfel was a co-author on an earlier study showing that controlling lead dust in the home lowered blood lead in children (Charney et al., 1983), and modified lead abatement practices definitionally included better dust clean-up. Farfel and Chisolm's decision to run this particular prospective "natural experiment" was explicitly motivated by their assessment that existing research had underestimated the hazards of current abatement procedures given the persistence of lead dust (Weitzman, 2020), as well as the political context in which only "a small number of states [had] established upgraded abatement requirements" (Farfel and Chisolm, 1990, 1240). The researchers' characterization of the relevant environment to include comparison of these particular methods of abatement thus not only implied the kinds of value judgments discussed above about what sorts of interventions ought to be expected from society, they also included judgments about the balance of inductive risks given the current state of scientific knowledge about abatement. Farfel and Chisolm compared some currently practiced interventions with others that they believed would probably be slightly better, despite the fact that lead poisoning could be completely prevented with provision of better housing. The researchers thus took as fixed that society would not provide better housing, since they state explicitly that "[r] esearch is needed to identify abatement strategies that will be practical" (1240, emphasis added) including "evaluation of costs and health and environmental outcomes of alternative abatement methodologies." (1244) Their mention of legal abatement requirements also places this research within the context of an inductive risk judgment that more evidence for the inadequacy of current abatement practices was necessary to draw that conclusion for decision- and policy-makers. A more precautionary approach to the inductive risks in the epistemology of the environmental lead hazard may well have found such conclusions already sufficiently justified, especially in the context of earlier work cited by-and in some cases performed by-these very researchers.

Despite the researchers' good intentions, and their generation of information that may have been useful for some decision- and policymakers, from an environmental justice and deontological ethical perspective this and subsequent research was questionable. Children in poor-quality housing were being used to demonstrate conclusively the ineffectiveness of environmental interventions that researchers probably already suspected were ineffective. Furthermore, the way this and subsequent research characterized the environmental lead hazard and thus identified the relevant environment reflected what lead researcher Herbert Needleman later called "pseudopragmatism" (Needleman, 2002, pp. 460-461). I will return to Needleman's argument below, as I now turn to these issues in more detail by analyzing Farfel and Chisolm's later, more controversial KKI abatement study.

\section{KKI's repair and maintenance lead abatement study: "pseudopragmatism," environmental racism, and the relevant environment of environmental health research}

In the previous section I argued that identifying and characterizing the relevant environment for environmental health research often involves complex tradeoffs between epistemic and non-epistemic values and thus requires coupling ethical and epistemic analysis. Questions of hazard identification, the construction of a causal model of the hazard, and operationalizing risk all show that identifying the relevant environment for environmental health research is thoroughly valueladen. This section uses these ideas to analyze Farfel and Chisolm's more controversial KKI lead abatement study. As mentioned above, Farfel and Chisolm (1990) foreshadowed this study in their earlier work by mentioning the need for research evaluating costs. The ambitious 1991 Department of Health and Human Services and Centers for Disease Control report, "A Strategic Plan for the Elimination of Childhood Lead Poisoning," included both the stated goal of full primary prevention and a cost-benefit analysis estimating that the overall benefits of such a nationwide, comprehensive program would exceed its costs by some $\$ 28$ billion (Binder \& Falk, 1991). However, this plan was immediately attacked by the lead industry, real estate, and insurance interests, as well as the usual political opponents of public spending, and even some physician groups (Needleman, 1998). The success of these attacks is indicative of the political environment of "pseudopragmatism" and racism that would characterize KKI's most controversial abatement study.

While their previous study took a "natural experiment" approach comparing cohorts living in homes that had experienced two different kinds of abatement, this study compared environmental and blood lead in children from families recruited to live in homes with several different planned "levels" of "repair and maintenance" (R\&M) lead abatement. Baltimore housing organization City Homes, owners of hundreds of lowincome rental properties, partnered with the Johns Hopkins KKI researchers and recruited participant families with young children to live in the homes with different levels of abatement. Most of the participant families came from majority-African American, historically redlined and segregated neighborhoods in East Baltimore. Other landlords with homes suitable for R\&M abatement also participated, apparently including one previously cited by the Baltimore Department of Health for violating local lead ordinances (Markowitz \& Rosner, 2013, p. 153) —appalling but unsurprising given the experiment's need for houses with existing lead hazards. It is notable that, as is common in biomedical research, the principal investigators Farfel and Chisolm never personally recruited any of the families. KKI developed a script used by City Homes to recruit families, which focused on potential benefits of participation including blood lead testing "at no charge." (Markowitz \& Rosner, 2013, p. 154).

The experiment had three treatment groups with known lead hazards and two control groups. Homes in treatment Groups 1-3 received increasing levels of abatement costing $\$ 1650, \$ 3500$, and $\$ 6500-7000$. $^{3}$ Control Group 4 homes had previously undergone full abatement by the city, and control Group 5 homes were built after 1978; these negative controls were expected to not contain lead hazards. The researchers did not use a control group of completely unabated homes, for obvious ethical reasons (Weitzman, 2020). The research was approved by the Johns Hopkins Institutional Review Board in the spring of 1992 after the board's head requested that the researchers emphasize the potential benefits to the children in each treatment group, since federal regulations - 45 CFR part 46, the "common rule" governing federally funded research with human participants enacted after the Tuskegee research scandal-prohibits the participation of children in projects with greater than "minimal risk" in which there is no potential benefit to the participating children (Markowitz and Rosner, 2013., 157). By 1997, data from 1993 to 1995 showed that the R\&M interventions in all three treatment groups showed statistically significant reductions in house dust, and while "children with very elevated blood lead levels appear to have benefited from all forms of abatement, no levels were reduced to the then-accepted level of concern, $10 \mu \mathrm{g} / \mathrm{dL}$ " (Markowitz and Rosner, 2013,

\footnotetext{
${ }^{3}$ The intervention in Group 1 included wet scraping of disturbed paint on interior surfaces and subsequent repainting, installing window well caps, repainting of exterior window trim and interior window sills, and vacuuming of all surfaces and windows with a high-efficiency particulate vacuum, and final wet cleaning (Lo and O'Connell 2005, p. 43), whereas homes in treatment Groups 2 and 3 included these interventions along with additional sealants and, in Group 3, window replacement and additional encapsulation of exterior trim.
} 
161). As mentioned above, there is no safe level of lead in a child's blood, and previous research had already shown that decreasing lead dust in homes can decrease blood lead levels in children.

While most participant children's blood lead levels had decreased during the course of the study, two parents of children involved in the study whose blood lead levels increased eventually sued KKI for negligence. In Grimes v. Kennedy Krieger, the Maryland Court of Appeals issued a scathing decision that sent the case to trial (Markowitz and Rosner, 2013). The court accused researchers of using children as "measuring tools," and controversially compared the research to the Tuskegee research scandal. They agreed with the plaintiffs' arguments that the research was actually non-therapeutic and that parents could not consent for children to enroll in non-therapeutic research, that the IRB review was inadequate, and that in the informed consent process and elsewhere the researchers failed in a duty to warn parents of potential risks. The court stated,

Otherwise healthy children ... should not be enticed into living in, or remaining in, potentially lead-tainted housing and intentionally subjected to a research program, which contemplates the probability, or even the possibility, of lead poisoning or even the accumulation of lower levels of lead in blood, in order for the extent of contamination ... to be used by scientific researchers .... (GrimesKrieger Institute, 2001).

While KKI eventually won the case at trial, this decision of the Maryland Appeals Court and the ethics of this research have been widely discussed in the biomedical research ethics literature since (e.g. Buchanan and Miller, 2006; Mastroianni \& Kahn, 2002; Spriggs, 2004; Wendler, 2004). While the study has been criticized on multiple grounds - for problems with the informed consent process and IRB review, and concerns about exploitation, for example-the main issue I focus on here is how these researchers' identification of the relevant environment in their study design reflected ethical and value judgments that were, at best, "pseudopragmatic" and at worst, racist. Pointing to these ethical issues is compatible with accepting that the researchers had good intentions and that the research probably benefited many study participants.

Farfel and Chisolm explained to the EPA, who provided funding for this study, that the epistemic goal of the research was to answer the question, "how much — or how little-'repair and maintenance' had to be done to gain what level of protection for the children?" (Markowitz and Rosner, 2013, 149). Reflecting on the subsequent controversy, Herbert Needleman expanded on the epistemic consequences of this "pseudopragmatic" focus on cost-effectiveness, and explained why it was actually not pragmatic at all:

Instead of asking, 'How can we develop a plan to spend US $\$ 32$ billion dollars over the next 15 years and eliminate all of the lead in dangerous houses?' [as suggested in the 1991 HHS report] the question became, 'How little can we spend and still reduce blood lead levels in the short term?' Completely ignored was the fact that lead in excess is found in exactly the same place where jobs and decent housing are rare. That comprehensive deleading could simultaneously create jobs, reduce unemployment and make [these neighborhoods] livable, never occurred to the self-styled pragmatists. (Needleman, 2002, 461)

Drawing on the discussion from the previous section, here Needleman can be interpreted as pointing to the fact that by identifying the relevant environment and characterizing the lead hazard and its abatement in such a narrow way, the researchers presupposed that a more comprehensive abatement policy focused on the goal of adequate primary prevention was neither forthcoming nor could be encouraged by their own research. Furthermore, a comprehensive policy of primary prevention could provide significant benefits for Baltimore's African American communities burdened with the ongoing legacies of housing segregation, environmental racism, and deindustrialization, and so could address ongoing racial injustice. The KKI researchers' implicit dismissal of this possibility is thus arguably tantamount to complicity in ongoing environmental racism.

The relevant environment for these researchers was restricted to the comparison of relatively inexpensive abatement interventions on "economic feasibility" grounds, namely that landlords would not pay for full abatement, since this cost—upwards of $\$ 20,000 —$ often exceeded the market value of the homes. At the time, many homes in these Baltimore neighborhoods were being abandoned. One central ethical question is thus whether such cost considerations within status quo political economic arrangements can justify research on less-expensive, probably lesseffective interventions. The use of a placebo group in biomedical research is widely considered unethical when a known-effective treatment is available (Shamoo \& Resnik, 2015). The same issue arose during the controversy over placebo-controlled clinical trials of the less-expensive "short course" of the anti-retroviral drug AZT to prevent mother-to-child transmission of HIV, conducted in countries in Asia and Africa where few could afford the known-effective longer course of the drug (Angell, 1997; Rothman \& Michaels, 1994). As Spriggs (2004) noted about the KKI case, "Knowing how to get rid of lead or reducing exposure was not as much of a problem as getting someone to pay for it" (179) and that the "value of the lead paint study seems to be that it is not acceptable for landlords to lose out financially but it is acceptable for children in low income housing to face the continuing risk of lead poisoning." (180)

Environmental and public health researchers reacted defensively to these arguments. In 2005, the US National Academy of Sciences' Committee on Ethical Issues in Housing-Related Health Hazard Research Involving Children, Youth, and Families wrote a report which attempted to contextualize and justify the KKI research as well as provide a summary of best practices for ethical research on housing hazards (Lo and O'Connell 2005). They include in this report a lengthy discussion of the "economics of rental housing," arguing:

[An] increase in affordable housing and broader requirements for abatement of hazards would offer prospects of genuinely healthy housing for all children ... the private low-income housing market provides limited incentives for landlords to do so. ... under current housing policies, there is a need for research to identify interventions that are not only effective at ameliorating housing health hazards but also cost effective. (Lo and O'Connell, 2005, 40, emphasis added).

However, whether "current housing policies" and the economics of the private low-income housing market should be taken as given, as the KKI researchers did in their research, or whether changes to housing policy ought to be contemplated explicitly within research, just is an example of the fundamental ethical dilemma of identifying the environment for environmental health research that I am pointing to in this paper. By the 1990s when this study was conducted, sufficient evidence supporting the argument for comprehensive primary prevention was arguably already in, even on cost-benefit grounds as analyzed in the 1991 HHS report. Farfel and Chisolm could have pointed to numerous studies, including their own, strongly supporting the claim that to be effective, lead abatement methods aimed at secondary prevention need to involve significant clean-up effort, and that more effort would likely yield healthier outcomes. Resources spent on this research possibly could have been used in experiments on cost-effectiveness of abatement methods on dust reduction outcomes alone, in empty homes. Such information could have potentially been used for a prospective study with participant families comparing abatement interventions thought to be both more or equally as effective as expensive procedures and more economical. As mentioned above, their own previous research had shown that reductions of lead-contaminated dust can reduce blood-lead levels in children (Charney et al., 1983).

Finally, the KKI researchers' identification of the relevant environment in the study was racist in the sense that it implied an obvious 
"double standard" of "minimal" environmental risk. The researchers claimed that children in the study would benefit and that they were not exposed to more than "minimal risk," understanding both as relative to what those particular children were likely to experience in their environment, not according to a single ethical standard of a reasonably safe environment (Wendler, 2004). The researchers reasoned that since these children were likely to be exposed to housing-related lead hazards anyway, it was permissible to use them to test the efficacy of these abatement practices, since they were likely to benefit from them relative to their current housing situation (Markowitz \& Rosner, 2013, p. 25). This same utilitarian-style marginalist argument was given in defense of the short-course AZT trials in terms of a relativized "local standard of care": without these trials, women participating would not have had access to antiretroviral treatment at all, so even a placebo-controlled trial would increase their expected welfare relative to a baseline of no research. There are several ways one might critique this reasoning, but the main problem with it in the context of the argument developed in this paper is that its simplistic utilitarian formulation-in particular its limited imagination in formulating the set of relevant feasible alternatives-abstracts researchers away from any responsibility for the underlying injustice of the background conditions. In KKI's case, the background consisted of the environmental racism of the lead hazard in Baltimore's highly segregated low-income housing. As biomedical scientists with significant social prestige, power, and access to public health resources, the KKI researchers indeed "chose sides" in pursuing limited lead abatement cost-effectiveness research. Instead of seeing themselves as making marginal interventions within a fixed political context, they could have seen scientific research as unavoidably entangled with political struggle, and as such partly responsible for that very political context. Considering the institutional and social positions of these researchers and the families that participated, the double standard inherent in the research was racist even if the researchers' intentions were to reduce harm, and even if they were successful by some plausible-albeit narrowly construed-utilitarian calculus.

While social norms around acknowledging and confronting the roles of structural racism in the US have shifted significantly since the 1990s, consideration of this broader view of research ethics may well have prevented this research ethics scandal. Indeed, Needleman recognized in 1998 that an "important factor is racism" in explaining the decades-long failure of comprehensive primary prevention: appalling racial inequalities in blood lead levels "due primarily to hypersegregation in houses built before 1940" were neglected in the context of "the current attitude of indifference toward problems of the poor and minorities" (Needleman, 1998, 1875). The KKI research did little to address this attitude of indifference, but rather seemingly internalized and reproduced it by conducting research involving a racist double standard of minimal risk.

In making this argument, I do not mean to suggest that all environmental health research on less-than-ideal interventions, or costeffectiveness research, is always, necessarily unethical. However, contrary to later defenders of research on "less expensive yet less effective interventions," (e.g. Buchanan and Miller, 2006, 784) environmental health research identifying the relevant environment narrowly with a focus on harm reduction within contexts of environmental injustice are arguably only justifiable in the context of ongoing, collaborative relationships between researchers and participants. That is, along with the satisfaction of Buchanan and Miller, (2006, 784) conditions-a "large population in need," the higher standard of care being much more expensive while a cheaper intervention is hypothesized to be "significantly effective," resource or political constraints preventing the distribution of the higher standard, and a "high degree of likelihood that the less costly intervention can and will be implemented on a large scale", along with other standard protections and oversight for research participants, such research ought to be co-designed with affected communities, in ways that materially benefit them and integrate broader "theories of change" that contextualize the relevant hazard. In the next section's concluding discussion, I turn to how relational research ethics might pursue identifying the environment for environmental health research.

\section{Concluding discussion: relational research ethics for identifying the relevant environment}

The preceding sections laid out how identifying the relevant environment for environmental health research-defining environmental hazards, characterizing causes, modeling risk, etc.-is thoroughly valueladen. I argued that the ethics scandal of the KKI lead abatement research could have perhaps have been avoided had the scientists involved recognized this and pursued research employing alternative ethicalepistemic judgments. This section concludes by turning to alternatives, particularly as they are articulated in environmental justice research (Bullard, 1999; Shrader-Frechette, 2002), community-based participatory research (Israel et al., 2005), and relational approaches to environmental health research ethics (Cordner et al., 2012). All of these approaches tend to center ongoing relationships between scientists, community members, and research participants. Their values include a commitment to a strong principle of environmental justice that sees equal protection from environmental hazards like lead poisoning as a human right (Bullard, 1999), and values the active participation of communities in developing and carrying out research to secure environmental health. If significant community participation in designing the research is taken to be an ethical constraint, then the fact that some participants may derive benefit from environmental health research on less-expensive and less-effective interventions is not sufficient for ethical permissibility. This section concludes by discussing how these alternative values might be embodied in identifying the relevant environment for environmental health research. Particularly, how might such research, rather than merely "collecting the data of damage" in ways that "[surveil] and [pathologize] already dispossessed communities" (Murphy, 2017, p. 496) serve instead to empower those communities?

Firstly, researchers should work with affected communities to identify and fully contextualize hazards. Anthropologist and science and technology studies scholar Michelle Murphy points to two "technoscientific epistemic habits" that characterize much of environmental health science and toxicology on chemical exposures (Murphy, 2017, p. 495). The first is to conceive of chemicals as "discrete entities," effectively mistaking the model of abstract structural diagrams from textbook chemistry for the chemicals themselves, which decontextualizes them by conceiving them outside of their relational-biochemical, biological, social, political, economic - contexts. Decontextualizing chemicals allows industry to easily "produce uncertainty about exposures" (Murphy, 2017) by modeling risk and placing blame elsewhere, as mentioned above in the case of the lead industry blaming parents of lead-poisoned children. Research motivated by the values mentioned above would work with affected communities to contextualize hazards, including their economic and political contexts. For example, Breckwich Vásquez et al. (2006) report on the community-based participatory research partnership between community environmental justice organization West Harlem Environmental ACTion, Inc. (WE ACT) and researchers with Columbia University's Center for Children's Environmental Health. Researchers collaborated with WE ACT activists to produce scientific evidence of particulate matter (PM2.5) exposure well above the Environmental Protection Agency's safety standard, which "reinforced community concerns about the disproportionate burden of diesel traffic and bus depots in Harlem." (104) The study led to installation of EPA air monitors, a complaint against the federal Department of Transportation, and an ultimately successful campaign by WE ACT to reduce particulate emissions from New York City buses by their conversion to so-called "clean diesel." The environmental health scientists reported to Breckwich Vásquez et al. that the research epistemically benefited from collaboration, as WE ACT community activists were likely to "question ... assumptions in a way that ... improve [d] the science" (Breckwich Vásquez et al., 2006) 
especially by drawing on their knowledge of the social contexts of particulate exposure. Of course, such collaborative research raises further questions about identifying the relevant community and "balancing scientific and community interests" (Resnik \& Kennedy, 2010), not only due to the potential for stigmatization but also the potential for scientists and community members to disagree about aspects of study design, data collection and analysis, interpretation of results, publication, etc. Navigating these latter issues necessitates clear communication and, possibly, prior agreements between researchers and their community collaborators about various ways the research could turn out (Corder et al., 2010).

Murphy's second "technoscientific epistemic habit" is biomedicine's documentation of damage to bodies caused by chemical exposures. Again, this has the potential to stigmatize because, as she puts it, "environmental biomedical research surveils and pathologizes already dispossessed communities." (Murphy, 2017, p. 496) Drawing on Eve Tuck's (2009) critique of "damage-centered" research, Murphy goes on to argue that, "Despite often antiracist intentions ... damage-based research has pernicious effects, placing the focus on chemical violence by virtue of rendering lives and landscapes as pathological." (Tuck, 2009) The pathologizing and stigmatizing effects of lead abatement research are especially worrying considering that many biomedical researchers of low-level lead exposures like Needleman often used behavioral outcome measures like IQ that had long been used in the context of scientific racism (Gould, 1996). More germane to the issue of identifying the relevant environment, one of the reasons why the KKI research was racist is that by employing the double standard of minimal risk they seemed to express tacit acceptance of the existing political environment of social neglect and racial stigma. While it might be impossible to completely avoid stigmatization and pathologization insofar as environmental health research usually involves documenting "damage" or disparities in environmental health hazards, collaborations between researchers and communities that deal explicitly with social and political contexts, including "theories of change" (Tuck, 2009, p. 423) have a better chance of producing research that is respectfully framed, ethically conducted, and beneficial to those communities in pursuing environmental health (Cordner et al., 2012). The case mentioned above of CBPR with WE ACT was credited with significant policy change, driven by community activists' own highly-detailed "theory of change." (Breckwich Vásquez et al., 2006, pp. 105-106). To close with an example from Baltimore, in their report on "lessons learned" in CBPR on children's environmental health, Israel et al. (2005) discuss how childhood asthma researchers at Johns Hopkins collaborated with a Community Advisory Board in East Baltimore, whose role "moved from 'advisory' toward sharing 'governance' of the project," including affecting overall study design so that all participants received beneficial interventions (1468). By expanding their understanding of the relevant environment from the proximate health hazard itself to the broader social, cultural, and political contexts of that hazard, and including affected communities in the production and governance of that research (Lo and O'Connell 2005, ch. 5), environmental health scientists can at least mitigate potential stigmatization involved in "documenting damage" by empowering those communities to improve their health.

\section{Acknowledgements}

Special thanks to Michael Weitzman and Dale Jamieson. Additional thanks to the participants in the Cogut Institute for the Humanities Seminar at Brown and two anonymous reviewers for helping to improve the manuscript.

\section{References}

Anderson, E. (2020). Feminist epistemology and philosophy of science. In E. N. Zalta (Ed.), The stanford Encyclopedia of philosophy. Spring 2020 Edition. https://plato.s tanford.edu/archives/spr2020/entries/feminism-epistemology/.

Angell, M. (1997). The ethics of clinical research in the third world. New England Journal Of Medicine, 337(12), 847-849.
Benfer, E. A. (2017). Contaminated childhood: How the United States failed to prevent the chronic lead poisoning of low-income children and communities of color. Harvard Environmental Law Review, 41, 493-561.

Benz, T. A. (2017). Toxic cities: Neoliberalism and environmental racism in Flint and detroit, Michigan. Critical Sociology, 45(1), 49-62.

Betz, G. (2013). In defence of the value free ideal. European Journal for Philosophy of Science, 3(2), 207-220.

Binder, S., \& Falk, H. (1991). Strategic plan for the elimination of childhood lead poisoning. Atlanta, GA: Centers for Disease Control.

Brandt, A. M. (1978). Racism and research: The case of the Tuskegee Syphilis study. Hastings Center Report, 8(6), 21-29.

Breckwich Vásquez, B., Minkler, M., \& Shepard, P. (2006). Promoting environmental health policy through community based participatory research: A case study from Harlem, New York. Journal of Urban Health, 83(1), 101-110.

Buchanan, D., \& Miller, F. G. (2006). Justice and fairness in the Kennedy krieger Institute lead paint study: The ethics of public health research on less expensive, less effective interventions. American Journal of Public Health, 96(5), 781-787.

Bullard, R. D. (1999). Dismantling environmental racism in the USA. Local Environment, 4(1), 5-19.

Charney, E., Kessler, B., Farfel, M., \& Jackson, D. (1983). Childhood lead poisoning. A controlled trial of the effect of dust-control measures on blood lead levels. New England Journal of Medicine, 309(18), 1089-1093.

Cordner, A., Ciplet, D., Brown, P., \& Morello-Frosch, R. (2012). Reflexive research ethics for environmental health and justice: Academics and movement building. Social Movement Studies, 11(2), 161-176.

Dignam, T., Kaufmann, R. B., LeStourgeon, L., \& Brown, M. J. (2019). Control of lead sources in the United States, 1970-2017: Public health progress and current challenges to eliminating lead exposure. Journal of Public Health Management and Practice, 25(1), S13-S22.

Douglas, H. (2000). Inductive risk and values in science. Philosophy of Science, 67(4), $559-579$.

Douglas, H. (2009). Science, policy, and the value-free ideal. Pittsburgh, PA: University of Pittsburgh Press.

Douglas, H. (2016). Values in science. In P. Humphreys (Ed.), The oxford Handbook of Philosophy of science. New York: Oxford University Press.

Elliott, K. C. (2009). The ethical significance of language in the environmental sciences: Case studies from pollution research. Ethics, Place \& Environment, 12(2), 157-173.

Elliott, K. C. (2011). Is a little pollution good for you? Incorporating societal values in environmental research. New York: Oxford University Press.

Elliott, K. C. (2017). A tapestry of values. New York: Oxford.

Elliott, K. C., \& McKaughan, D. J. (2014). Nonepistemic values and the multiple goals of science. Philosophy of Science, 81, 1-21.

Farfel, M. R., \& Chisolm, J. J. (1990). Health and environmental outcomes of traditional and modified practices for abatement of residential lead-based paint. American Journal of Public Health, 80(10), 1240-1245.

Flora, G., Gupta, D., \& Tiwari, A. (2012). Toxicity of lead: A review with recent updates. Interdisciplinary Toxicology, 5(2), 47-58.

Frank, D. M. (2017). Making uncertainties explicit: The Jeffreyan value-free ideal and its limits. In K. C. Elliott, \& T. Richards (Eds.), Exploring inductive risk. New York: Oxford.

Frank, D. M. (2019). Ethics of the scientist qua policy advisor: Inductive risk, uncertainty, and catastrophe in climate economics. Synthese, 196, 3123-3138.

Gilbert, S. G., \& Weiss, B. (2006). A rationale for lowering the blood lead action level from 10 to 2 microg/dL. Neurotoxicology, 5, 693-701.

Gould, S. J. (1996). The mismeasure of man. New York: Norton.

Grimes v Kennedy Krieger Institute (2001), 366 Md 29, 782 A 2d 807. Accessed November 2, 2020.

Haraway, D. J. (1989). Primate visions: Gender, race, and Nature in the World of modern science. New York: Routledge.

Hunter, P. R., \& Fewtrell, L. (2001). Acceptable risk. In L. Fewtrell, \& J. Bartram (Eds.), In world health organization (WHO), water quality: Guidelines, standards, and health (pp. 207-227). London: IWA Publishing.

Israel, B., Parker, E. A., Rowe, Z., Salvatore, A., et al. (2005). "Community-Based participatory research: Lessons learned from the centers for children's environmental health and disease prevention research. Environmental Health Perspectives, 113(10), 1463-1471.

James, W. (1979/1897). The will to believe and other essays in popular philosophy. Cambridge, MA: Harvard University Press.

Jeffrey, R. C. (1956). Valuation and acceptance of scientific hypotheses. Philosophy of Science, 23(3), 237-246.

Katikireddi, S. V., \& Valles, S. (2015). Coupled ethical-epistemic analysis of public health research and practice: Categorizing variables to improve population health and equity. American Journal of Public Health, 105(1), e36-e42.

Korthals, M. (2011). Ethics of environmental health. In R. Chadwick, et al. (Eds.), The SAGE Handbook of healthcare ethics (pp. 416-429). SAGE.

Kuhn, T. S. (1977). Objectivity, value judgment, and theory choice. In T. Kuhn (Ed.), The essential tension (pp. 320-339). Chicago: University of Chicago Press.

Levins, R. (1996). Ten propositions on science and antiscience. Social Text, 46/47, $101-111$.

Levins, R., \& Lewontin, R. (1985). The dialectical biologist. Cambridge, MA: Harvard University Press.

Link, B. G., \& Phelan, J. (1995). Social conditions as fundamental causes of disease. Journal of Health and Social Behavior, 35, 80-94.

Longino, H. (1990). Science as social knowledge: Values and objectivity in scientific inquiry. Princeton, NJ: Princeton University Press.

Longino, H. (1995). Gender, politics, and the theoretical virtues. Synthese, 104(3), 383-397. 
Longino, H. (1996). Cognitive and non-cognitive values in science: Rethinking the dichotomy. In L. H. Nelson, \& H. Nelson (Eds.), Feminism, science, and the philosophy of science (pp. 39-58). Dordrecht: Kluwer.

Lönnroth, K., Jaramillo, E., Williams, B. G., et al. (2009). Drivers of tuberculosis epidemics: The role of risk factors and social determinants. Social Science \& Medicine, 68(12), 2240-2246.

Lo, B., \& O'Connell, M. E. (Eds.). (2005). Ethical Considerations for Research on housingrelated health hazards involving children. Washington, DC: National Academies Press.

Markowitz, G., \& Rosner, D. (2013). Lead wars: The Politics of Science and the Fate of America's children. Berkeley, CA: University of California Press.

Mastroianni, A. C., \& Kahn, J. P. (2002). Risk and responsibility: Ethics, Grimes v Kennedy krieger, and health research involving children. American Journal of Public Health, 92(7), 1073-1076.

Murphy, T. F. (2004). Case studies in biomedical research ethics. Cambridge, MA: MIT Press.

Murphy, M. (2017). Alterlife and decolonial chemical relations. Cultural Anthropology, 32(4), 494-503.

Needleman, H. L. (1998). Childhood lead poisoning: The promise and abandonment of primary prevention. American Journal of Public Health, 88, 1871-1877.

Needleman, H. L. (2002). What is not found in the spreadsheets. Neurotoxicology and Teratology, 24, 459-461.

Resnik, D. B. (2012). Environmental health ethics. New York: Cambridge University Press. Resnik, D. B., \& Kennedy, C. E. (2010). Balancing scientific and community interests in community-based participatory research. Accountability in Research, 17(4), 198-210.

Resnik, D. B., \& Roman, G. (2007). Health, justice, and the environment. Bioethics, 21(4), 230-241.

Roberts, D. (2012). Fatal invention: How science, politics, and big business Re-create Race in the twenty-first century. New York: The New Press.

Rose, G. (1985). Sick individuals and sick populations. International Journal of Epidemiology, 14, 32-38.

Rosner, D., \& Markowitz, G. (2016). Building the world that kills us: The politics of lead, science, and polluted homes, 1970-2000. Journal of Urban History, 42(2), 323-345.
Rothman, K. J., \& Michaels, K. B. (1994). The continuing unethical use of placebos. New England Journal Of Medicine, 331, 394.

Rudner, R. (1953). The scientist qua scientist makes value judgments. Philosophy of Science, 20, 1-6.

Shamoo, A., \& Resnik, D. (2015). Responsible conduct of research (3 ${ }^{\text {rd }}$ ed.). New York: Oxford University Press.

Shrader-Frechette, K. (2002). Environmental justice: Creating equality, reclaiming democracy (New York: Oxford).

Spriggs, M. (2004). Canaries in the mines: Children, risk, non-therapeutic research, and justice. Journal of Medical Ethics, 30(2), 176-181.

Steele, K. (2012). The scientist qua policy advisor makes value judgments. Philosophy of Science, 79, 893-904.

Tuana, N. (2013). Embedding philosophers in the practices of science: Bringing humanities to the sciences. Synthese, 190(11), 1955-1973.

Tuck, E. (2009). Suspending damage: A letter to communities. Harvard Educational Review, 79(3), 409-427.

Valles, S. (2018). Philosophy of population health: Philosophy for a New public health era. New York: Routledge.

Väyrynen, P. (2019). Thick ethical concepts. In E. N. Zalta (Ed.), The stanford encyclopedia of philosophy (summer 2019 edition). https://plato.stanford.edu/archives/sum2019/ entries/thick-ethical-concepts/.

Ward, Z. B. (2020). On value-laden science. In Studies in the History and Philosophy of science Part A. https://doi.org/10.1016/j.shpsa.2020.09.006

Washington, H. A. (2006). Medical apartheid: The dark History of medical Experimentation on black Americans from colonial Times to the present. New York: Doubleday.

Weitzman, M. (2020). Personal communication.

Wendler, D. (2004). Risk standards for pediatric research: Rethinking the grimes ruling. Kennedy Institute of Ethics Journal, 14(2), 187-198.

Whitehead, L. S., \& Buchanan, S. D. (2019). Childhood lead poisoning: A perpetual environmental justice issue? Journal of Public Health Management and Practice, 25(1), S115-S120. 